\title{
Internal limiting membrane peeling Vs no peeling in primary vitrectomy for macula off retinal detachment: A comparative study
}

\author{
Islam Awny ${ }^{1}$, Mohamed Anber ${ }^{1}$, Mohammad Hussein Mousa ${ }^{1}$, Hassan Ali \\ Mourtada $^{2}$ \\ 1- Department of ophthalmology, Sohag faculty of medicine, Sohag University, \\ Sohag \\ 2- Department of ophthalmology, Kasr El Ainy faculty of medicine, Cairo \\ University, Cairo
}

\begin{abstract}
Purpose:To compare the visual outcome and the rate of epiretinal membrane formation after primary vitrectomy with internal limiting membrane peeling Vs no peeling for patient with macula off retinal detachment.

Patients and methods: This was a Prospective comparative uncontrolled case series. The study enrolled 30eyeswith rhegmatogenous retinaldetachmentwith macula off subjected to primary vitrectomy , and classifiedinto 2 groups, Group A cases subjectedto primary vitrectomywithoutinternallimiting membrane peeling and group B casessubjected to primary vitrectomy, with internal limiting membrane peeling, Assessment of best corrected visual acuityand rate of epiretinal membrane formation after removal of silicone oil had been done.

Results:This study included 30 eyes of 30 patients, 16 (53.33\%) were males and 14 $(46.67 \%)$ were females, the mean age of studied patients was $(43.37 \pm 10.40)$ years old. There was no statistically significant difference in mean $\operatorname{logMAR}$ BCVA after silicone oil removal $(1.18 \pm 0.29$ for group A versus $0.99 \pm 0.38$ for group $\mathrm{B} ; \mathrm{P}=$ 0.12).OCT done for all cases after silicone oil removal after 6 months and show that; epiretinal membrane with cystoid macular edema is formed in 5 cases in group A while ERM is not formed in any cases in group $\mathrm{B}(\mathrm{P}=0.04)$, IS / OS line is interrupted in 6 cases in group $A$ and in 3 cases $(P=0.43)$ as regarding foveal contour; it is lost in 5 cases and preserved in 10 cases in group A while in group B the foveal contour is preserved in 13 cases, lost in 1 case and flat in 1 case $(\mathrm{P}=0.06)$, while comparing the mean of the central foveal thickness shows no statistically significant difference $295.73 \pm 129.46$ for group A versus $237.6 \pm 47.60$ for group B; P $=0.66$.
\end{abstract}

Conclusion:There was no statistically significant difference in mean visual acuity after silicone oil removal in both procedures.however, the epiretinal membrane formation was absent in group B with ILM peeling in comparison to group A.

Keywords:Epiretinal membrane, vitrectomy, internal limiting membrane, rhegmatogenous retinal detachment.

Internal limiting membrane peeling Vs no peeling in primary vitrectomy for macula off retinal detachment: A comparative study

Islam Awny, Mohamed Anber, Mohammad Hussein Mousa, Hassan Ali Mourtada

\section{Introduction}

Rhegmatogenous (from "rhegma," rent, or fissure) retinal detachments occur when ocular fluid dissects under a full-thickness retinal tear.The primary pathogenic process in rhegmatogenous retinal detachment is the formation of a retinal break, 
through which the liquefied vitreous passes. 1

There are typical risk factors that increase the danger of rhegmatogenous retinal detachment, principal among them shortsightedness, cataract surgery, and trauma. The higher incidence of retinal detachment in patients with these risk factors is attributed to points of particularly strong adhesion between the vitreous body and the retina ${ }^{2,3,4}$

A proportion of patients with retinal detachment will be asymptomatic. Those who are asymptomatic usually have very peripheral or inferior detachments that progress slowly. ${ }^{5}$

The principle of retinal detachment surgery is to find and seal all the retinal breaks (using cryotherapy or laser) and to 'splint' the break while the retinopexy develops thus creating adhesions within the retina to prevent the accumulation of sub-retinal fluid.The urgency of retinal detachment repair depends on the type of retinal detachment and the threat to the macula. Studies have shown that the duration of macular involvement is the most important factor in determining the final visual acuity in a patient with a macula-off retinal detachment. $^{6}$

As 20-gauge PPV became more widely used, A major problem was the development of iatrogenic retinal breaks, specifically those at the sclerotomy site. ${ }^{7}$ Small gauge pars plana vitrectomy was popularized by GildoFujii who introduced a sutureless, transconjunctival, 25-gauge PPV system for use in a variety of surgical cases in 2002. ${ }^{8}$

Peeling the internal limiting membrane of the retina has become a very common procedure performed by vitreoretinal surgeons. The combination of new microsurgical instrumentation with the availability of different dyes to stain this thin and transparent membrane has facilitated the performance of internal limiting membrane peeling, reducing the time and trauma associated with this maneuver. Internal limiting membrane peeling has been used to treat a variety of retinal pathologies, including fullthickness macular hole, epiretinal membrane, and macular edema. ${ }^{9}$

Epiretinal membrane is one of the most common complications of rhegmatogenous retinal detachment after vitrectomy, and internal limiting membrane may play a role of scaffold on various cells that develop ERM. The ILM is composed of the basement membrane of Muller cells, proteoglycans, and type VI collagen, and is an important structure in the formation of the vitreo retinal interface. 10

The aim of our study was to compare the visual outcome and the rate of epiretinal membrane formation after primary vitrectomy with internal limiting membrane peeling Vs no peeling for patient with macula off retinal detachment.

\section{Patients and methods:}

This was a Prospective comparative uncontrolled case series. The study enrolled 30 eyes with rhegmatogenous retinal detachment with macula off subjected to primary vitrectomyat Sohag University Hospital, Sohag, Egypt and Dar AlOuyn Hospital, Cairo, Egypt.

The study was approved by the medical ethics committee of the faculty of medicine, Sohag University. The Declaration rules of Helsinki were respected throughout our study, and written informed consent was obtained from all patients for the treatment sequence.

Patients will be excluded from participating in the study if one or more of the following criteria were found; previous vitreous surgery,previous glaucoma filtration 
surgery,patients with inadequate follow up, macular hole retinal detachment and Patients with grade $\mathrm{C}$ PVR.

All patients were interviewed and underwent ophthalmologic examinations both preoperatively and postoperatively. Examinations included bestcorrected visual acuity in LogMAR, intraocular pressure, anterior segment, and fundus examination with Volk 78D lens (Volk Optical Inc., Mentor, OH).

Data were collected concerning the length of time between the last operation and the silicone oil removal, duration of the follow-up period after silicone oil removal, and number and type of operations.
Patients wereclassifiedinto 2 groups, Group A cases subjected to primary vitrectomy withoutinternallimiting membrane peeling and group B cases subjected to primary vitrectomy, withinternallimiting membrane peeling (fig. 1), Patients of both groups received postoperativetreatmentconsisting of antibioticseye drops for 4 weeks and steroids.

All patients werefollowed up for 6 months. Patients wereseen on the first postoperativeday, then on the first and thirdweek, and theneverymonth.

Assessment of best correctedvisualacuity and rate of epiretinal membrane formation by OCT afterremoval of silicone oilhad been done.

Fig. 1: peeling of the ILM withstain

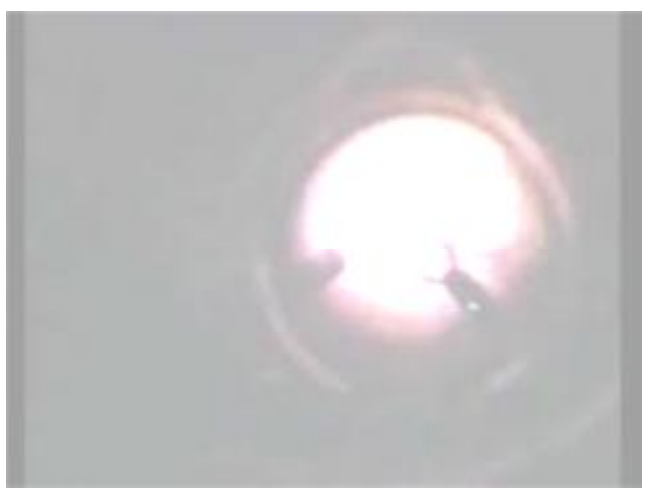

\section{Results}

This study included 30 eyes of 30 patients, $16(53.33 \%)$ were males and 14 (46.67\%) were females, the mean age of studied patients was $(43.37 \pm 10.40)$ years old.

Females were $5(33.33 \%)$ patients in group A and $9(60.00 \%)$ patients in group B, while males were $10(66.67 \%)$ patients in group A and $6(40.00 \%)$ patients in group $\mathrm{B}(\mathrm{P}=0.14)$. there was no statistically significant difference between the average age for both groups $(50.07 \pm 10.87$ in group A versus $56.67 \pm 9.09$ in group $\mathrm{B} ; \mathrm{P}=0.08)$. There was no significant difference according to the extent of retinal detachment between both groups.

There was no statistically significant difference in mean $\operatorname{logMAR}$ BCVA after silicone oil removal $(1.18 \pm 0.29$ for group A versus $0.99 \pm 0.38$ for group $\mathrm{B} ; \mathrm{P}=$ 0.12). Table 1 OCT done for all cases after silicone oil removal after 6 months and show that; epiretinal membrane with cystoid macular edema is formed in 5 cases in group A while ERM is not formed in any cases in group $\mathrm{B}(\mathrm{P}=0.04)$ Table 2 , IS / 
SOHAG MEDICAL JOURNAL

Vol. 21 No.2 July 2017
Internal limiting membrane peeling Vs no peeling Islam Awny.et al

OS line is interrupted in 6 cases in group A and in 3 cases $(P=0.43)$ as regarding foveal contour; it is lost in 5 cases and preserved in 10 cases in group A while in group $\mathrm{B}$ the foveal contour is preserved in 13 cases, lost in 1 case and flat in 1 case (P $=0.06)$, while comparing the mean of the central foveal thickness shows no statistically significant difference $295.73 \pm 129.46$ for group A versus $237.6 \pm 47.60$ for group $\mathrm{B} ; \mathrm{P}=0.66$.

Table 1: Comparison between the two groups as regard logMAR BCVA

\begin{tabular}{|c||c|c||c|}
\hline \multicolumn{1}{|c|}{ Variables } & Group (A): & Group (B) & P value \\
\hline \hline visual acuity after & $1.18 \pm 0.29$ & $0.99 \pm 0.38$ & 0.12 \\
SOR Mean \pm SD & $1.3(0.6-1.5)$ & $1.1(0.3-1.5)$ & \\
Median (range) & & & \\
\hline \hline visual acuity after & & $2(13.33 \%)$ & \\
SOR & 0 & $1(6.67 \%)$ & \\
0.3 & $1(6.67 \%)$ & $2(13.33 \%)$ & \\
0.6 & $1(6.67 \%)$ & $1(6.67 \%)$ & \\
0.8 & $2(13.33 \%)$ & $1(6.67 \%)$ & \\
0.9 & $1(6.67 \%)$ & $3(20.00 \%)$ & \\
1 & $1(6.67 \%)$ & $1(6.67 \%)$ & \\
1.1 & $1(6.67 \%)$ & $2(13.33 \%)$ & \\
1.2 & $4(26.67 \%)$ & $2(13.33 \%)$ & \\
1.3 & $4(26.67 \%)$ & & \\
\hline
\end{tabular}

Table 2: Comparisonbetween the two groups as regard ERM

\begin{tabular}{|c||c|c|c|}
\hline ERM & $\begin{array}{c}\text { Group (A): without } \\
\text { ILM peeling }\end{array}$ & $\begin{array}{c}\text { Group (B): with ILM } \\
\text { peeling }\end{array}$ & P value \\
\hline \hline No & $10(66.67 \%)$ & $15(100 \%)$ & 0.04 \\
Yes & $5(33.33 \%)$ & 0 & \\
\hline
\end{tabular}

There was no statistically significant difference in mean IOP between two groups (10.07 \pm 1.87 for group A versus $9.6 \pm 1.35$ for group $\mathrm{B} ; \mathrm{P}=0.44$ ).

Table 3: Comparison between the two group as regard IOP

\begin{tabular}{|c|c|c|c|}
\hline Variables & $\begin{array}{l}\text { Group (A): without } \\
\text { ILM peeling }\end{array}$ & $\begin{array}{c}\text { Group (B): with ILM } \\
\text { peeling }\end{array}$ & P value \\
\hline $\begin{array}{l}\text { IOP } \\
\text { Mean } \pm \text { SD } \\
\text { Median (range) }\end{array}$ & $\begin{array}{c}10.07 \pm 1.87 \\
10(8-15)\end{array}$ & $\begin{array}{l}9.6 \pm 1.35 \\
10(8-12)\end{array}$ & 0.44 \\
\hline $\begin{array}{l}\mathbf{I O P} \\
8 \\
10 \\
12 \\
15\end{array}$ & $\begin{array}{c}4(26.67 \%) \\
8(53.33 \%) \\
2(13.33 \%) \\
1(6.67 \%)\end{array}$ & $\begin{array}{c}5(33.33 \%) \\
8(53.33 \%) \\
2(13.33 \%) \\
0\end{array}$ & 0.77 \\
\hline
\end{tabular}




\section{Discussion}

In this prospective study, the incidence of epiretinal membrane formation in group A without ILM peeling was 5 eyes $(33.33 \%)$, while there was no

cases of epiretinal membrane formation in group B with ILM peeling $\mathrm{P}=0.4$. Similar results to this study were found by Aras et $\mathrm{al}^{11}$, who did not find any macular pucker in 20 eyes with proliferative vitreoretinopathy $\leq$ D1 after vitrectomy with ILM peeling for retinal detachment, but they observed epimacular membrane formation in $27.3 \%$ eyes after vitrectomy without ILM peeling, So this study confirmed the hypothesis that ILM peeling causes inhibition of the process of visible fibrosis and formation of epimacular membrane.

According to visual acuity, there was general improvement in the mean logMAR BCVA in cases with ILM peeling than other cases without ILM peeling, although there was no statistically significant difference in the mean $\log$ MAR BCVA in both groups $\mathrm{P}=0.66$, which may be explained by pre operative macular detachment that decreased the net result of visual improvement. Nam KY et $\mathrm{al}^{12}$ showed that The overall visual acuity was better in the group with ILM peeling than that without ILM peeling, although the difference was not significant may be due to macular detachment. However when the macula - on group was analyzed, the mean visual acuity was better in the ILM peeling group than in the non - ILM peeling group, and a significant difference was found at the 12 month follow up $(p=0.03)$. This showed that the visual acuity was affected by the epiretinal membrane that occurred after primary vitrectomy for rhegmatogenous retinal detachment, implying that removal of the ILM results in better visual acuity by preventing the occurrence of a post operative epiretinal membrane compared with patients who did not undergo ILM peeling.

Studying the pre operative factors, we found that extent of retinal detachment, number of breaks, and status of the lens were insignificant for the development of epiretinal membrane, extent of retinal detachment was (one quadrant detachment was 1 eye "6.67 $\% "$ in group A and zero eye in group B, two quadrants detachment was 7 eyes "46.67 \%" in group A and 6 eye "40.00 \%" in group B, three quadrants detachment was 3 eyes "20.00\%" and 4 eyes "26.67 \%", and four quadrants detachment was 4 eyes "26.67 \%" in group $\mathrm{A}$ and 5 eyes " $33.33 \%$ " in group B. $\mathrm{P}=0.3$ ), number of breaks (one break in 8 eyes "53.33 \%" in group A and 5 eyes "33.33 \%" in group B, two breaks in 5 eyes " $33.33 \% "$ in group A and 8 eyes " $53.33 \% "$ in group $\mathrm{B}$, and three breaks in 2 eyes "13.33 \%" in group A and 2 eyes " $13.33 \%$ " in group B. $P=0.5$ ), and status of lens was (it was clear in 7 eyes "46.67 \%" in group $\mathrm{A}$ and 10 eyes "66.67 \%" in group B, cataractus in 6 eyes "40.00\%" in group A and 10 eyes "66.67 \%" in group B, and pseudophakic in 2 eyes "13.33\%" in group $\mathrm{A}$ and zero eye in group $\mathrm{B}$. $\mathrm{P}$ $=0.27$ ).

Similar observations reported by Martínez-Castillo $\mathrm{V}^{13}$, this study done on 312 eyes of 307 patients and 28 of the 312 eyes "8.97 \%" developed epiretinal membrane during the post operative period, pre operative risk factors in this study were insignificant. Extent of retinal detachment was (in ERM group one quadrant in 12 "4 \%", two quadrants in 101 eyes "36 \%", three quadrants in 107 eyes "38 \%", and four quadrants in 64 eyes "23\%", and in non - ERM group one quadrant in 3 eyes "11\%", and two quadrants in 10 eyes "36 \%", three quadrants in 9 eyes "32 \%", and four quadrants in 6 
eyes "21 \%".P = 0.483). Number of breaks was (in ERM group single break in 160 eyes "56\%" and multiple breaks in 124 eyes "44\%", and in non - ERM group single break in 15 eyes "54 \%" and multiple breaks in 13 eyes "46 \%". P = 0.778). status of the lens was (in ERM group Aphakia in 17 eyes "6 \%" and pseudophakia in 267 eyes "94 \%" and in non - ERM group Aphakia in 0 "0 \%" and 28 eyes "100 $\% " . \mathrm{P}=0.183$ ).

\section{References}

1. Gonin J. The evolution of ideas concerning retinal detachment within the last five years: The William Mackenzie Memorial Lecture, 1933. Br J Ophthalmol. 1933;17(12):726-740.

2. Mitry D, Charteris DG, Fleck BW, Campbell H, Singh J: The epidemiology of rhegmatogenous retinal detachment: geographical variation and clinical associations. $\mathrm{Br} \mathrm{J}$ Ophthalmol 2010; 94: 678-84.

3. Van de Put MAJ, Hooymans JMM, Los LI, Dutch Rhegmatogenous Retinal Detachment Study Group: The incidence of rhegmatogenous retinal detachment in The Netherlands. Ophthalmology. 2013; 120: 616-22.

4. Haimann MH, Burton TC, Brown CK: Epidemiology of retinal detachment. Arch Ophthalmol 1982; 100: 289-92.

5. Pocklinghorne PJ and Craig JP. Analysis of Symptoms associated with rhegmatogenous retinal detachments. Clinical and Experimental Ophthalmology, 1994. 32: 603-606.

6. Burton TC. Recovery of visual acuity after retinal detachment involving the macula. Trans Am Ophthalmol Soc. 1982; 80: 475-97.
7. MachemerR.,\&Hickingbotham D. The three-port microcannular system for closed vitrectomy. Am J Ophthalmol, Vol. 100, (October 1985), pp. (590592).

8. Fujii GY, de Juan E. Jr, Humayun MS, Pieramici, DJ, Chang, TS, Awh, C., $\mathrm{Ng}, \quad$ E., Barnes, A., Wu, SL, \&Sommerville, DN. A new 25-gauge instrument system for transconjunctivalsutureless vitrectomy surgery. Ophthalmology, Vol. 109, No. 10, (October 2002), pp. (1807-12).

9. Abdelkader E, Lois N. Internal limiting membrane peeling in vitreo-retinal surgery.SurvOphthalmol. 2008 JulAug;53(4):368-96.

10.Katria RC, Zamani M, Berinstein DM, et al. Incidence and Characteristics of Macular Pucker Formation After Primary Retinal Detachment Repair by Pars Plana Vitrectomy Alone. Retina, 28: 744-748; 2008.

11. Aras C, Arici C, Akar S, et al. Peeling of Internal Limiting Membrane During Vitrectomy for Complicated Retinal Detachment Prevents Epimacular Membrane Formation. Graefes Arch ClinExpOphthalmol, 247: 619-623; 2009.

12.Nam KY, Kim JY. Effect of Internal Limiting Membrane Peeling on the Development of Epiretinal Membrane after Pars Plana Vitrectomy for Primary Rhegmatogenous Retinal Detachment. Retina, 35: 880-885;2015.

13.Martínez-castillo V, Boixadera A, Boixadera L, et al. Epiretinal Membrane after Pars Plana Vitrectomy for Primary Psudophakic and Aphakic Rhegmatogenous Retinal Detachment, Incidence and outcomes. Retina, 32: 1350-1355; 2012. 